\title{
Spanish Composition Errors from a Combined Classroom of Heritage (L1) and Non-heritage (L2) Learners: A Comparative Case Study
}

\author{
John M. Ryan \\ University of Northern Colorado, USA
}

\begin{abstract}
In a world of declining institutional budgets, decreasing student enrollments in departments that until now may have had the luxury of separate composition classrooms for heritage and non-heritage students, not to mention individual student schedule limitations, the steady increase in enrollment of L1 or heritage students in composition classrooms which were before primarily geared toward L2 learners has created a new reality and the urgency to rethink the organization, sequence, and emphasis placed on topics and structures in the classroom. The purpose of this case study was to conduct a comprehensive analysis of L1 and L2 student composition error data collected from a sample of fifteen students enrolled in a Spanish Composition (SPAN 302) class at the University of Northern Colorado (UNC). Specific objectives for this project were to determine from the data collected: 1) the frequencies with which L1 and L2 student participants committed word- and sentence-level errors in their compositions; 2) how error frequencies compare between L1 and L2 students over a semester's time, and in particular, with the writing of a series of five different compositions, each targeting a more advanced level of writing proficiency; and 3) how knowledge of both similarities and differences between these two groups might be applied to enhance the author's current pedagogical model that could work for future students from both groups in a single classroom.
\end{abstract}

Index Terms-composition studies, error analysis, Spanish, combined classrooms

\section{PREvious Composition ERRor STUDIES}

Student error analysis is an area of investigation that not only helps to shed light on how students learn, but it also serves as a pedagogical tool that can be used to increase students' awareness of the most common types of errors to avoid. The topic of writing or composition among L2 students is not a new area of investigation (Nas \& Van Esch, 2014; DeHaan \& Van Esch, 2005; Valdés et al. 1992; Schneider \& Connor, 1990), nor is the focus of error analysis of compositions, in Spanish or otherwise (Van Beuningen, 2010; Carduner, 2008; Truscott, 2007; Ferris, 2004). Previous studies that have examined comparisons between L1 and L2 writing in Spanish include Silva (1993) who concluded that, compared to L1 writing, that produced by L2 learners is a more involved process and less efficient in that there is less planning, fewer ideas, and less thorough revisions. In another study, Roca de Larios et al. (2002) identify certain strategies that L1 and L2 learners share such as problem-solving strategies and an interactive approach to composing text. A study that underscores a major difference in L1 and L2 writing is Schoonen et al. (2009) which asserts that the L2 writer is in a sense required to work harder because s/he may have to call on additional cognitive resources to compensate for inadequacies in vocabulary or other linguistic deficiencies. What appears to be lacking in the area of L1 and L2 writing are data-driven studies on how L1 and L2 writing errors compare and how knowledge of similarities and differences might contribute to an intervention model that could improve student writing in a combined classroom.

\section{Project Design And Methodology}

The statistical design of this study is one that involves the analysis of error frequency data. As such, the following three phases all supported the collection, analysis, and interpretation of project data, as follows:

Phase 1: Data collection (grading of compositions) and coding of student errors

Throughout Spring 2017 semester, the fifteen student participants of this study wrote and submitted five compositions of increasing difficulty, each ranging between 300 and 750 words, and targeting successively more advanced levels of writing proficiency. The course utilized the textbook La escritura paso a paso by Lapuerta \& Mejía (2008) as a basis to collect data since its chapters (and corresponding composition assignments) are based on successive levels of proficiency, as prescribed by ACTFL. All 75 compositions were graded and errors classified and coded according to the categories appearing in Table 1. 
TABLE 1.

ERROR CATEGORIES USED TO CODE STUDENT COMPOSITION ERRORS

Word-level categories

\begin{tabular}{|c|c|c|}
\hline 1) Accent missing/wrong & 6 ) Incorrect number & 11 ) Verb in wrong tense \\
\hline 2 ) Adverb incorrect & 7 ) Indirect obj. pronoun & 12 ) Verb in wrong mood \\
\hline 3 ) Capital letter incorrect & 8 ) Prepositional pronoun & 13 ) Wrong gender \\
\hline 4 ) Copula choice & 9 ) Spelling error & 14 ) Wrong number (singular/plur \\
\hline 5 ) Direct object pronoun & 10 ) Verb form incorrect & 15 ) Wrong word \\
\hline \multicolumn{3}{|l|}{ Sentence-level categories } \\
\hline 1 ) Adjective placement & 6 ) New structure needed & 11) Punctuation mistake \\
\hline 2 ) Article missing & 7 ) Noun-adjective agreement & 12 ) Reflexive \\
\hline 3 ) Conjunction wrong/missing & 8 ) Part of speech incorrect & 13 ) Subject pronoun redundant \\
\hline 4 ) English structure & 9 ) Personal 'a' is missing & 14 ) Subject-verb agreement \\
\hline 5 ) Makes no sense & 10 ) Preposition wrong/missing & 15 ) Word(s) not necessary \\
\hline
\end{tabular}

Phase 2: Tally, sorting, and entry of student error data, review and analysis

Once all 75 compositions were graded and coded for word- and sentence-level errors, these were then tallied, sorted, and entered into Excel. During this second phase, error data were reviewed and analyzed, as well as further disambiguated in order to take into consideration the following variables: 1) individual student composition error patterns; and 2) composition type (descriptive, summary, narrative, expository, and persuasion) to determine: a) whether certain patterns were more prevalent than others in certain types of writing, and b) the rate of persistence of certain errors over time.

Phase 3: Data interpretation and reflection

The last phase of the project was spent completing the analysis, enumerating project findings, and reflecting on the implications this work has on a future model for teaching composition in combined classrooms of L1 and L2 students.

\section{Participants}

Both L1 and L2 data for this experiment were collected and analyzed as part of a 2017 summer grant program at the University of Northern Colorado. ${ }^{1}$ Originally intended to identify the error frequencies of non-native (L2) students alone, the project exceeded its original scope in that four of the fifteen students of the cohort identified themselves as heritage learners with previous personal or non-academic exposure to Spanish. This necessitated early separation and tracking of these students from the remaining eleven, essentially creating both a second, previously unconsidered project cohort of L1 students, as well as a previously unanticipated project variable, namely heritage/non-heritage status.

Given the wide discrepancy between the number of L1 $(n=4)$ and L2 $(n=11)$ participants, data for this study are presented both in terms of the number of tokens per error, as well as percentage frequency. Also, in both cases of L1 and L2 students, emphasis is placed on the most common errors committed by each group for each error category. ${ }^{2}$

\section{Teaching method}

My approach to teaching Spanish composition includes the use of a computer laboratory in order to maximize the amount of time students use class time to practice their writing. This method has proven to be quite effective in creating a composition "boot camp," not only in terms of increased instructor-guided writing, but the additional experiences of group writing and peer-editing among students as well, both of which I have found to be particularly effective for the sharing of information and acquisition of advanced skills.

\section{COMPARISON OF L1 AND L2 StUdENT PARTICIPANT DATA}

\section{Overall error frequencies for $\mathrm{L} 1$ and $\mathrm{L} 2$ students}

The first of the major differences found between L1 and L2 students of this study was in terms of the number of errors committed by each group, both overall and for each error category. As might be expected, L1 learner participants as a group committed significantly fewer errors overall $(n=252)$ as compared to those by their L2 counterparts $(n=$ 1,801). Notwithstanding the large difference in number between L1 $(n=4)$ and L2 $(n=11)$ participants, the average number of errors per L1 participant $(n=63.0)$ was still found to be strikingly lower than that for L2s $(n=163.72$, Comparison of L1 and L2 errors becomes even more interesting when one looks at individual behaviors by each group at word- and sentence-levels, as illustrated in Figure 1.

\footnotetext{
${ }^{1} 2017$ UNC Summer Support Initiative Award No. QS232. Also, publication of this article was funded in part by the University of Northern Colorado Fund for Faculty Publication.

${ }^{2}$ In both cases, the top five errors for both L1 and L2 students constituted the majority of errors, ranging overall between $66.55 \%$ and $84.18 \%$. of all errors. As the data will also show, in the case of L1 students, a full $84.18 \%$ of all word-level errors were represented by the top four error categories.
} 


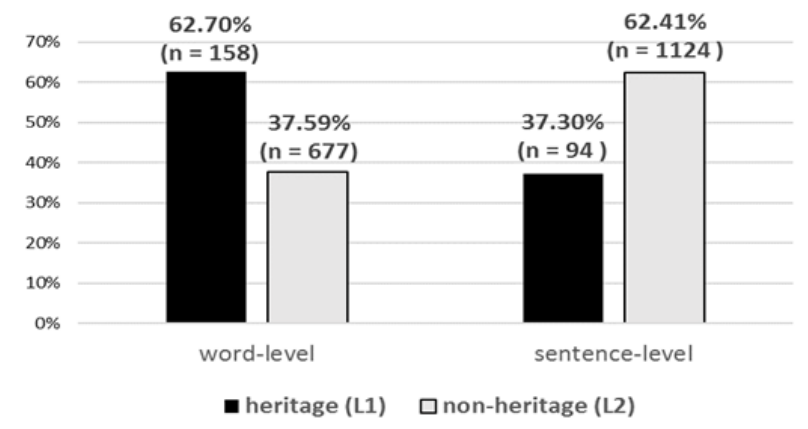

Figure 1: L1 versus L2 student percentage error results for all compositions

The most immediate observation of Figure 1 is that, despite the wide difference in the average number of errors reported above for each group, heritage and non-heritage participants of the study exhibited almost precise inverse tendencies when it came to word- versus sentence-level errors. According to the figure, L1 speakers committed a higher percentage of errors at word- $(62.7 \%)$ than at sentence- level $(37.3 \%)$, while L2s committed fewer errors at word$(37.59 \%)$ than at sentence-level $(62.41 \%)$. This initial, more general finding of the data confirms previous anecdotal observations that each group has differing needs when it comes to the acquisition of composition skills, and particularly at word- and sentence-levels.

The following section of this paper examines the data further in terms of word and sentence level errors for both L1 and 12 participants of this study.

\section{Word-level Errors}

A closer look at the word-level errors committed by L1 and L2 students of the study yielded the following observations.

L1 student errors at word level

Table 2 shows the data for all word error categories (in order from highest to lowest) for L1 students:

TABLE 2:

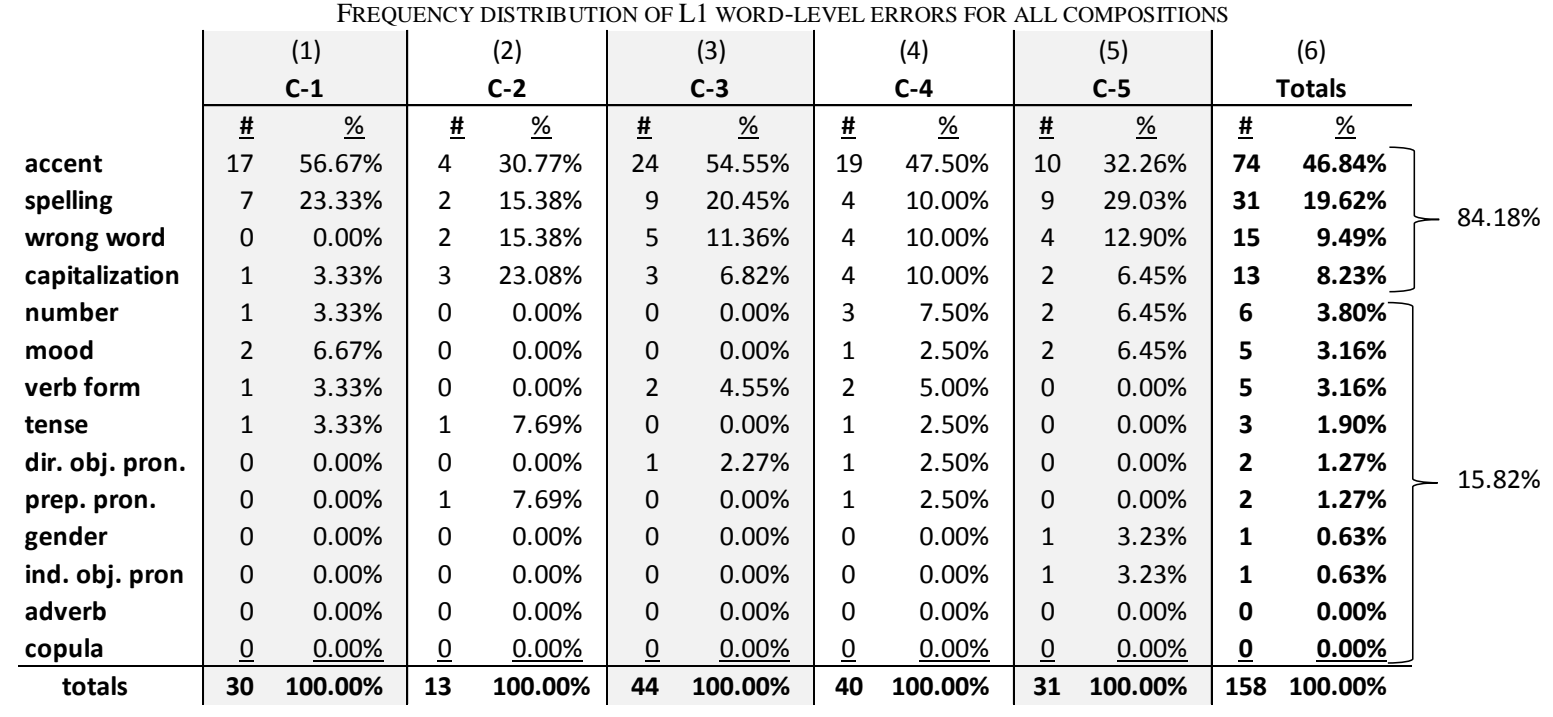

According to the data in Table 2, a full $84.18 \%$ of all word-level errors committed by L1 participants is represented by errors in the first four categories, from highest to lowest as indicated in column (6), namely: 1) incorrect (or missing) accent mark $(\mathrm{n}=74 ; 46.84 \%) ; 2)$ incorrect spelling $(\mathrm{n}=31 ; 19.62 \%) ; 3)$ use of the wrong word $(\mathrm{n}=15 ; 9.49 \%)$; and 4$)$ incorrect capitalization $(\mathrm{n}=13 ; 8.23 \%)$.

Some examples from the data of these four most common categories of L1 word level-errors are underlined and/or explained below:

(1) Accent error: "Llegue a Italia..." with the intended meaning: 'I arrived in Italy..." (The first person singular preterit tense form of llegar 'to arrive' requires a written accent on the final syllable, as in Llegué.)

(2) Spelling error: “...invitado por el reí...” with the intended meaning: '...invited by the king...' (the word for 'king' in Spanish should be spelled rey. The way it is spelled by the student means 'I laughed.')

(3) Wrong word: "Esperamos encontrar especias..." with the intended meaning: "we hope to find species...' (Especias is another Spanish word that means 'spices.' The word for 'species' in Spanish is especies.) 
(4) Capitalization: “...montañas en colorado...” with the intended meaning: '...mountains in Colorado...' (Colorado is a proper noun in Spanish and should be capitalized).

All other errors committed by L1 students at word level (totaling 15.82\%) occurred on average with less frequency (each below $4 \%$ of total errors in each case), including: 5) grammatical number $(\mathrm{n}=6 ; 3.8 \%)$; 6 ) incorrect $\operatorname{mood}(\mathrm{n}=5$; $3.16 \%) ; 7)$ incorrect verb form $(\mathrm{n}=5 ; 3.16 \%) ; 8)$ incorrect verb tense $(\mathrm{n}=3 ; 1.90 \%)$, 9) incorrect or missing direct object pronoun $(\mathrm{n}=2 ; 1.27 \%)$; and 10$)$ incorrect prepositional pronoun $(\mathrm{n}=2 ; 1.27 \%)$; etc.

L1 word-level trends between compositions

If one compares error results for each of the five compositions (abbreviated by C-1, C-2, etc.) for L1 participants (represented in Table 2 by the last row of totals for columns (1) through (5)), one sees between C-1 and C-2 an immediate drop in the total number of errors (from $n=30$ to $n=13$ ), and then a resurgence between C-2 and C-3 (from $\mathrm{n}=13$ to $\mathrm{n}=44$ ), after which it steadily declines from C-3 to C-5, finishing at a total of 31 tokens.

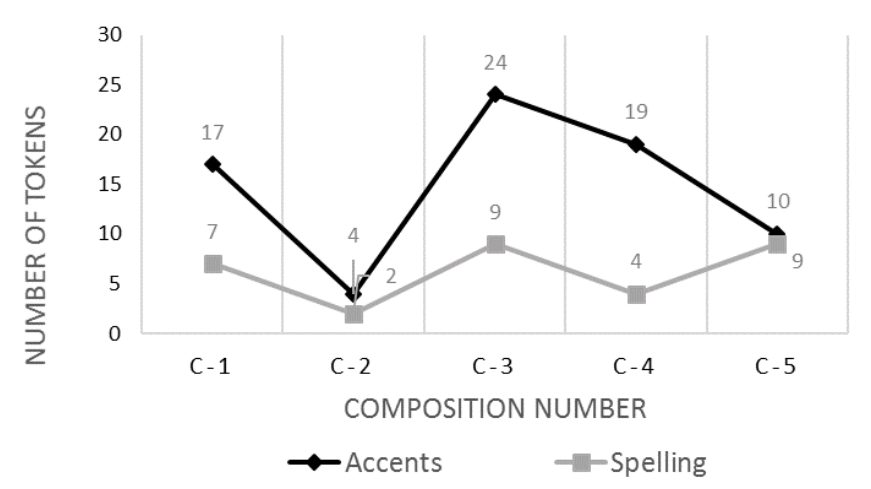

Figure 2: Cross-composition fluctuations in L1 top two word-level errors

A closer look at the individual error categories across all compositions suggests that the most noticeable fluctuations appear in terms of "accent," and "spelling," particularly between the first and second compositions. Figure 2 illustrates these fluctuations.

The large drop in errors between C-1 and C-2, as illustrated in Figure 2, might be explained by the very nature of composition 2, whose purpose was to draw information from two fictitiously published (and biased) articles in order to create a single, new unbiased article (Lapuerta \& Mejía, 2008). It should not be very surprising that errors would drop in the areas of accents or spelling for $\mathrm{C}-2$ since most of the words that would be used in the new composition could have appeared in the two fictitious articles that had been provided to students as source material. If one accepts these fluctuations as determined by the nature of the composition, it would seem that L1 students of the study actually improved over time in their correct use of accents, but only remained relatively stable in terms of their spelling.

Just as any significant drop in errors must be addressed, so too must noticeable increases, like that occurring for these same students between $\mathrm{C}-2$ and C- 3 . $^{3}$ Once again, as suggested for the drop in overall L1 errors between C-1 and C-2, it may be that the nature of composition 3 , which was a personal narrative, significantly more complex than $\mathrm{C}-2$, and definitely more involved than $\mathrm{C}-1$.

L2 student errors at word level

Table 3 provides the data for all word error categories (in order from highest to lowest) for L2 students of this study:

\footnotetext{
${ }^{3}$ One must mention here that if the results for $\mathrm{C}-2$ are an anomaly in the sense that they could have been influenced by the nature of the information provided to the student beforehand, then it follows that the sharp increases that appear between C-2 and C-3 might not be, in fact, as sharp, or even exist at all, if under other circumstances C-2 errors were much higher.
} 
TABLE 3:

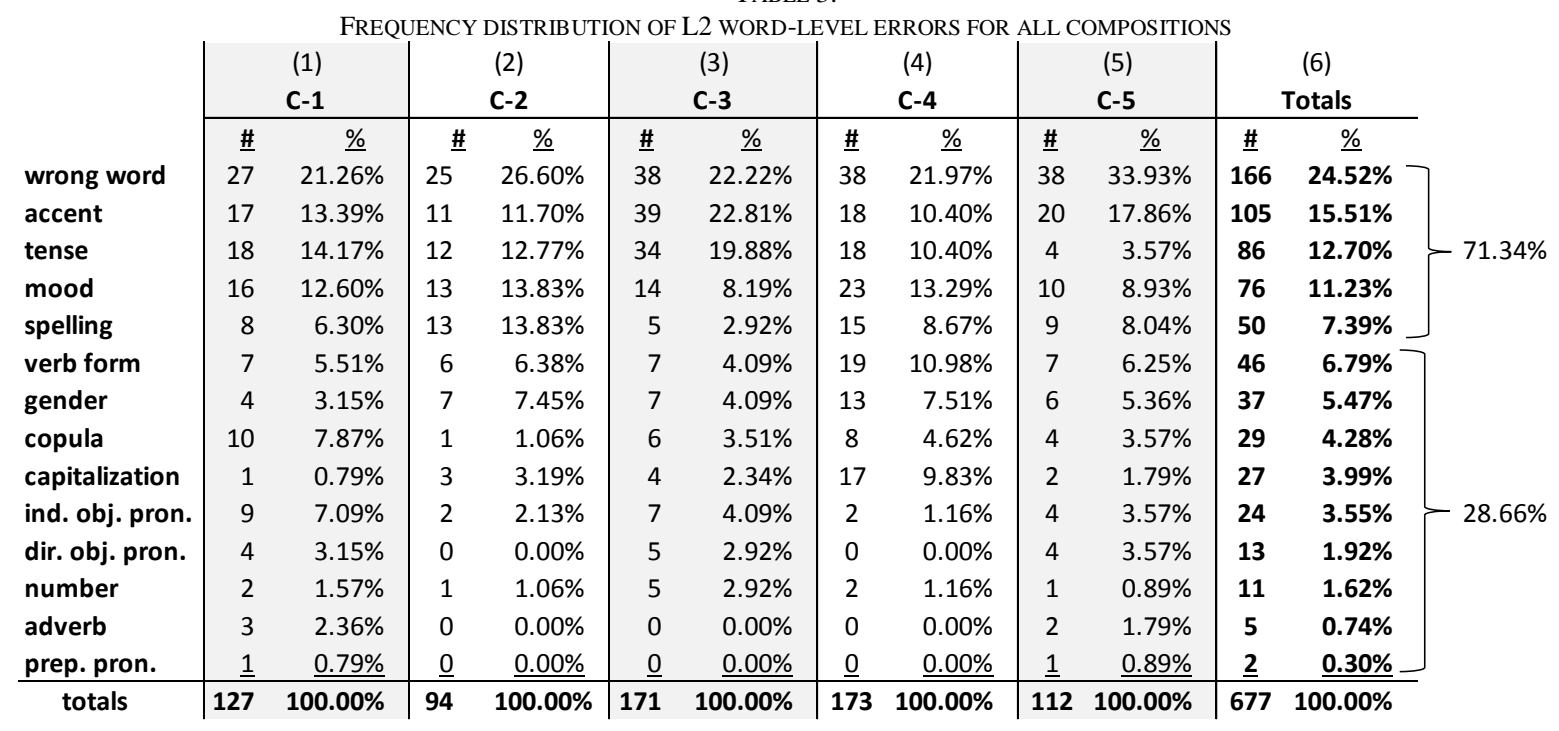

According to the data in Table 3, a full 71.34\% of all word-level errors committed by L2 participants is represented by errors in the first five error categories (from highest to lowest), as indicated in column (6), namely: 1) use of the wrong word $(\mathrm{n}=166 ; 24.52 \%) ; 2)$ incorrect (or missing) accent mark $(\mathrm{n}=105 ; 15.51 \%) ; 3)$ incorrect tense $(\mathrm{n}=86$; $12.7 \%)$; 4 incorrect $\operatorname{mood}(\mathrm{n}=76 ; 11.23 \%)$; and 5$)$ incorrect spelling $(\mathrm{n}=50 ; 7.39 \%)$.

Some examples from the data of these five most common categories of L2 word level-errors are underlined and/or explained below:

(5) Wrong word: "Respuesta de la película..." with the intended meaning: 'Review of the movie...' (Respuesta is another Spanish word that means 'answer.' The word for 'review' in Spanish is reseña.)

(6) Accent error: "mi mama ..." with the intended meaning: 'My mom...' (The Spanish word for 'mom' requires a final written accent as in mamá.)

(7) Tense error: "Ella tuvo miedo." with the intended meaning: 'She was scared.' (Here, the student uses the preterit tense which in Spanish is used to describe a one-time action, or its beginning or end. To express an ongoing feeling or emotion, the imperfect tense is used and so the correct form here should be tenía.)

(8) Mood error: "Quiero una guitarra que tiene...." with the intended meaning: 'I want a guitar that has...' (The verb in the subordinate clause must be in the subjunctive mood, required by the volitional verb of the matrix clause querer 'to want'.)

(9) Spelling error: "ㅅy mucha comida..." with the intended meaning: 'There is a lot of food...' (The third person existential copula is spelled as hay.)

All other word-level errors committed by L2 students (totaling 28.66\%) occurred on average with less frequency. These included incorrect verb form $(n=46 ; 6.79 \%)$; incorrect gender $(n=37 ; 5.47 \%)$, and incorrect choice of the Spanish copulas serlestar $(\mathrm{n}=29 ; 4.28 \%)$, among others.

L2 word-level trends between compositions

If one compares the total number of word errors by L2 participants for each of the five compositions (represented in Table 2 by the last row of totals for columns (1) through (5)), one sees a somewhat different pattern from that which we observed for L1 students of this study. Although there also appears to be a drop between C-1 and C-2 as there was for L1 students, it is much less pronounced for L2s (exhibiting a drop by only 2 to 6 tokens, depending on the category). The more prominent fluctuation for L2 word errors appears to have occurred between C-2 and C-3, surging from a total of 94 to 171 tokens. Total L2 errors remain stable between C- 3 and C-4, but by C-5, total L2 errors drop considerably to 112 tokens.

A closer look at L2 individual error categories across all compositions suggests that the most noticeable fluctuations appear in the categories of "wrong word," "accent," and "tense." Figure 3 illustrates these fluctuations. 


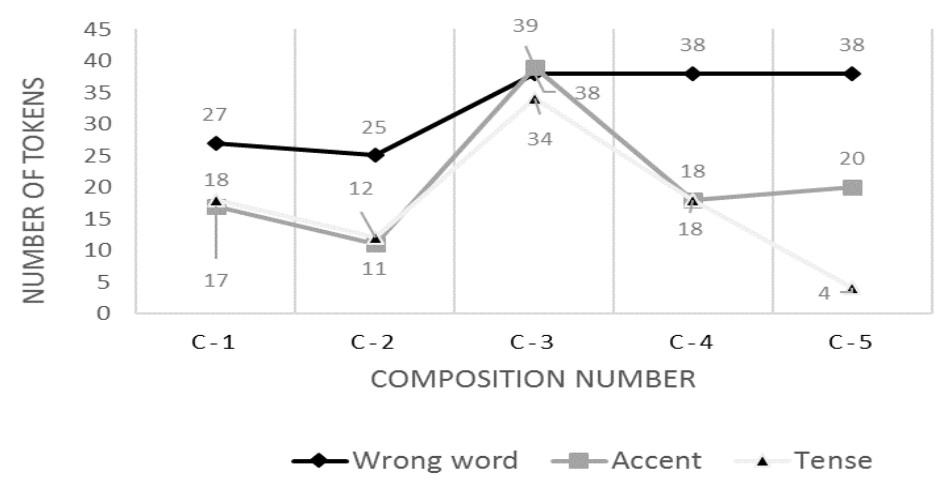

Figure 3: Cross-composition fluctuations in L2 top three word-level errors

Figure 3 suggests that use of the wrong word, the highest of all word-level errors of L2 students, increases in occurrence by $\mathrm{C}-3$ and continues to be a significant problem for this group up to and including the last composition. We see, however, a different pattern for the next two errors, those of accent and tense, which, like wrong word use, also increase exponentially. The difference for these other two errors is that we see improvement after the surge at $\mathrm{C}-3$, with dramatic drops for both between $\mathrm{C}-3$ and $\mathrm{C} 4$, after which accents appear to stabilize at approximately the same rate (with a negligible increase of 2 tokens) by C-5, whereas tense errors continue to improve between C-4 and C-5. The reason suggested for why errors appear to increase dramatically for L2 students, both overall and within certain categories between C-2 and C-3, is the same proposed for this similar surge in errors for L1 students, between these same compositions, namely, the advancement to a more complex type of composition, requiring a creative personal narrative which was based on several days of diary entries, but rewritten in third person, but (Lapuerta \& Mejia, 2008).

One last item to be addressed for L2 participants is what appears to be a more widespread distribution of surges in word-level errors at C-4. For all other compositions, although errors appeared in other categories, they did so much less frequently. Once again, the reason proposed for these surges within C-4 is the nature of the composition. C-4's purpose, being to write a small grant proposal required greater diversity in structure than the previous three compositions.

L1 and L2 word-level errors compared

When comparing the most common word-level errors between L1 and L2 learners of this study we see both similarities and differences in terms of the types of errors committed, their frequencies, or the degree of difficulty of one composition over another. Before making comparisons between L1 and L2 students which are composition-specific, we start with the comparison of overall error patterns. Figure 4 compares total percentage frequencies of L1 and L2 wordlevel errors found for all five compositions combined. 


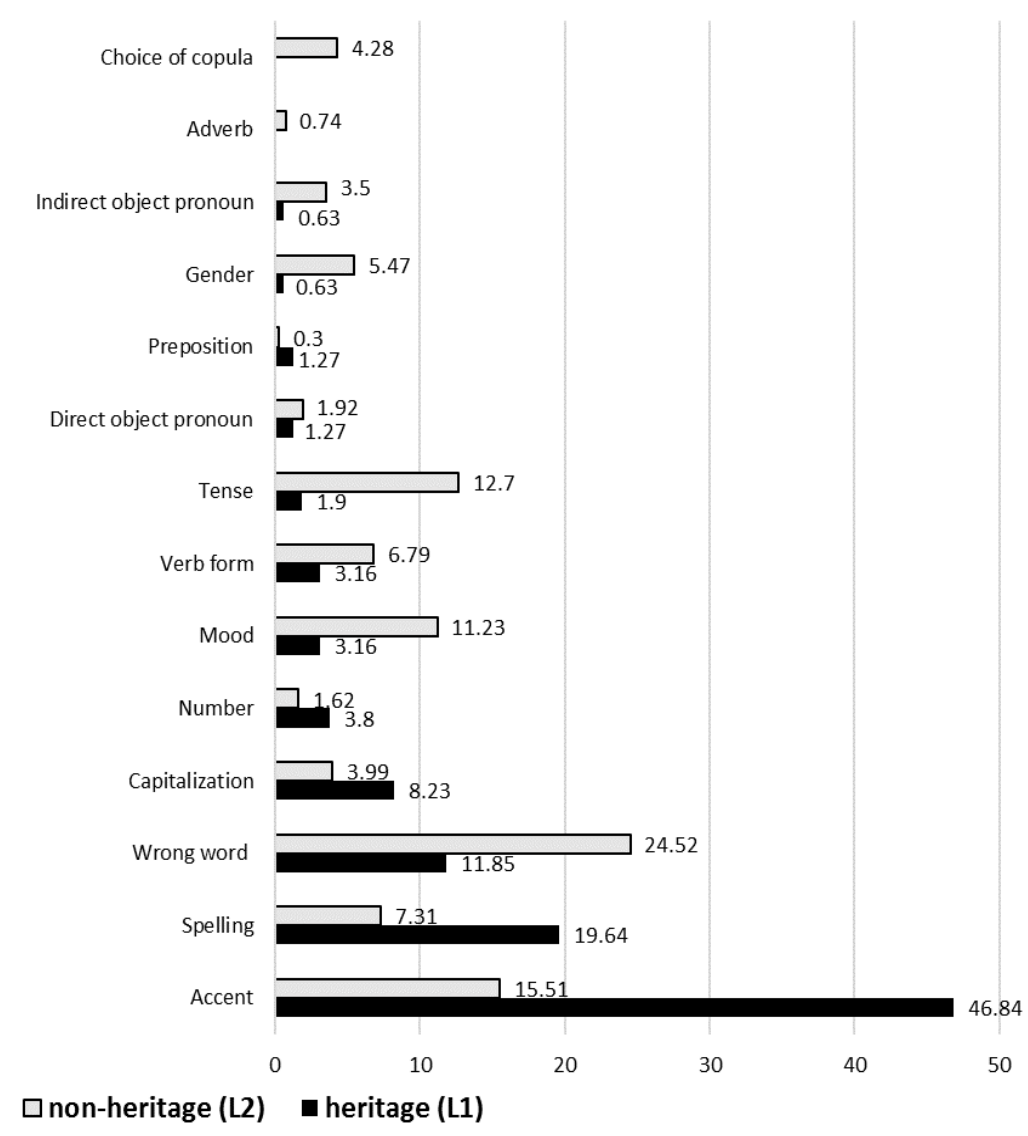

Figure 4: Comparative percentage distribution of overall L1 and L2 word -level errors

Figure 4 suggests that both L1 and L2 groups commit many errors of the same category at word level; however, despite similarity of category, the most important difference is percentage of occurrence. In other words, although L1 and L2 student participants both exhibited similar problems such as accent marks, spelling, tense and gender, the extent to which these errors are committed by each group is very different. For example, according to Figure 4, L1 speakers committed accent errors $46.84 \%$ of the time, whereas L2 students did so at a much lower overall rate of $15.51 \%$. On the other hand, L2 speakers of the study chose the incorrect verb tense $12.7 \%$ of the time, whereas L1 speakers only $1.9 \%$. The two errors L1 participants were never found to commit were copula choice (which L2 participants committed $4.28 \%$ of the time) and incorrect adverb usage (which L2 participants committed at a rate of less than $1 \%(0.74 \%)$. Other error categories in Figure 4 likewise illustrate differences in the extent to which L1 and L2 commit similar errors at word level.

Also interesting in terms of compared L1 and L2 word-level errors are similarities between the groups in terms of trends and fluctuations exhibited between the five compositions of this study. If one compares the composition error totals of Tables 2 and 3, repeated here in isolation, and graphically in Figure 5, it is clear that both groups exhibited strikingly similar trends and fluctuations in each case between contiguous compositions. As Figure 5 shows, despite the wide difference in the total number of tokens for each group (explained previously as due to the difference in number of students representing each group), the percentage of error for each composition is where one must focus attention. In all five cases there appears to be a striking correspondence between both groups as to the percentage of overall error, suggesting that both L1 and L2 students of the study experienced similar levels of difficulty as they moved from one composition to the next of this study. 


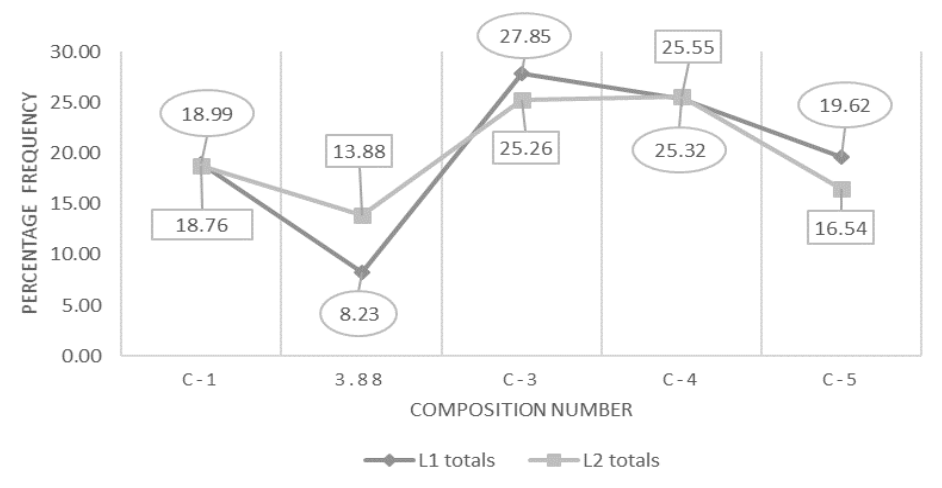

Figure 5: Overall L1 and L2 word error frequencies for all compositions

\section{Sentence-level Errors}

A closer look at the errors committed by L1 and L2 students of the study at sentence-level yielded the following observations.

Ll errors at sentence level

Table 5 shows the data for all sentence error categories (in order from highest to lowest) for L1 students:

TABLE 5:

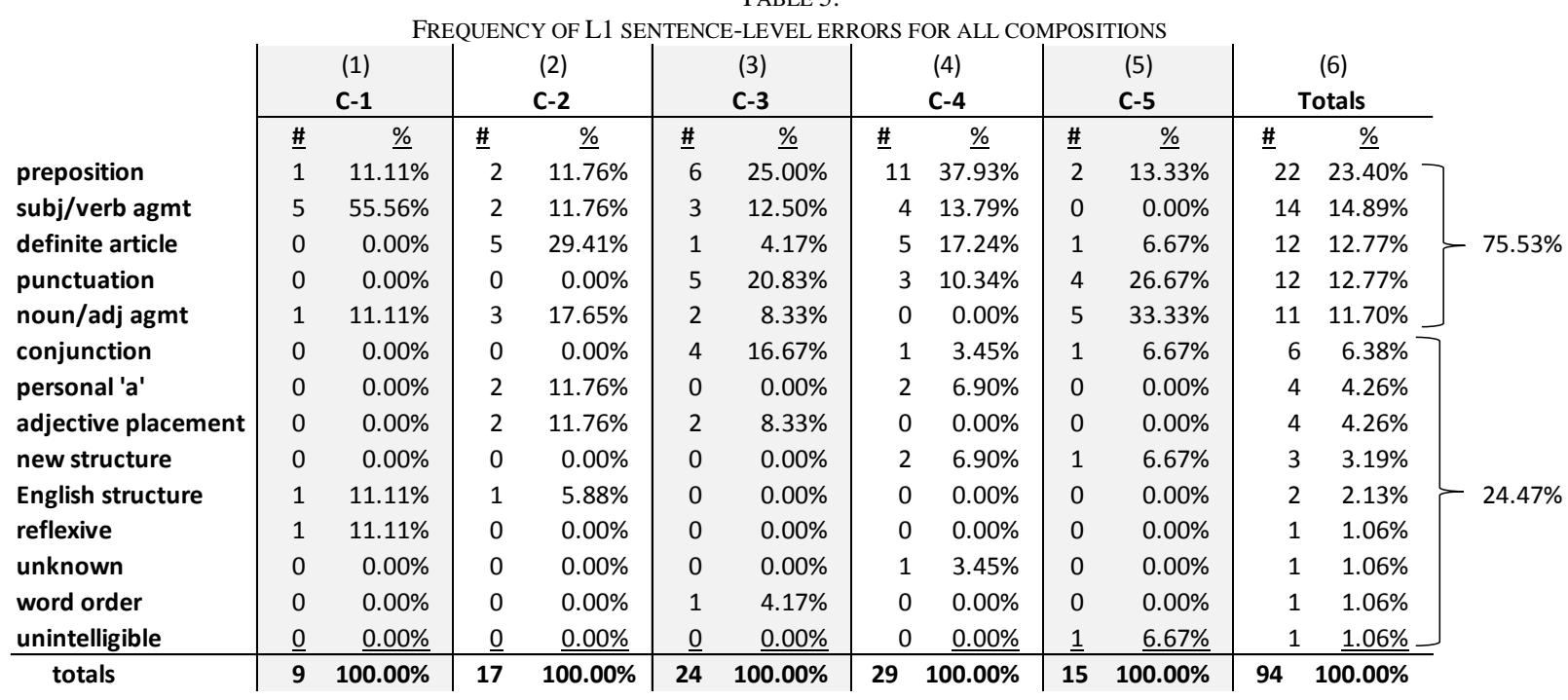

According to the data in Table 5, a full $75.53 \%$ of all sentence-level errors committed by L1 participants is represented by errors in the first five error categories (from highest to lowest), as indicated in column (6), namely: 1) incorrect use or missing preposition $(\mathrm{n}=22 ; 23.40 \%) ; 2)$ subject/verb agreement $(\mathrm{n}=14 ; 14.89 \%)$; 3) a missing definite article $(\mathrm{n}=12 ; 12.77 \%) ; 4)$ faulty punctuation $(\mathrm{n}=12 ; 12.77 \%)$; and 5$)$ faulty noun/adjective agreement $(\mathrm{n}=11$; $11.70 \%)$.

Some examples from the data of these five most common categories of L1 sentence level-errors are underlined and/or explained below:

(10) Wrong or missing preposition: “...faltar muchos eventos” with the intended meaning: '...to miss many events.' (The verb faltar 'to miss' requires the preposition $a$ or 'to.')

(11) Faulty subject/verb agreement: “...una gran población que lo apoyan." with the intended meaning: “....a large population which supports him' (In formal written Spanish writing, a collective (singular) noun requires a singular verb, and therefore, the correct form here should be apoya.)

(12) Missing definite article: “Gente duda que..." with the intended meaning: 'People doubt that.' (Here, the student uses the word gente in a general sense and therefore must precede the word with the definite article, in this case la.)

(13) Faulty punctuation: "Llegó la hora esperada las 4:30..." with the intended meaning: 'the expected time arrived, $4: 30 \ldots$ (Like English, in Spanish a comma should be used to indicate the pause which separates these units, particularly in writing that represents a stream of consciousness.)

(14) Faulty noun/adjective agreement: "Querida mamá y papa," with the intended meaning: 'Dear mom and dad,' (The way this is written, querida only modifies mamá, and not papá, suggesting that the student only considers her mother to be dear and not her father. The intended form would be queridos, which modifies both coordinated terms.) 
All other sentence-level errors committed by L1 students of this study (totaling 24.47\%) occurred on average with less frequency. Some of these included an incorrect conjunction $(n=6 ; 6.38 \%)$, a missing personal ' $a$ ' $(n=4 ; 4.6 \%)$ or the incorrect placement of an adjective $(n=4 ; 4.6 \%)$, among others.

L1 sentence-level trends between compositions

If one compares total sentence-error results for each of the five compositions for L1 participants (represented in Table 5 by the last row of totals for columns (1) through (5)), one sees a different pattern from that which appeared for this same group in terms of word-level errors. For example, rather than the drop in errors that was seen between C-1 and C-2 for word-level errors, one sees rather an overall steady increase in the number of errors between the first four compositions, with a final decrease between C-4 and C-5. I would argue that this is the trend that one would expect from students who are writing successively more complicated compositions, but who, after a semester's time of writing and rewriting, improve with the last composition.

Despite the overall appearance of a steady increase in error generation until the final composition, a closer look at L1 individual error categories across all compositions, however, does reveal some noticeable fluctuations, particularly in the categories of "preposition," "subject/verb agreement," and "definite article," as illustrated in Figure 6.

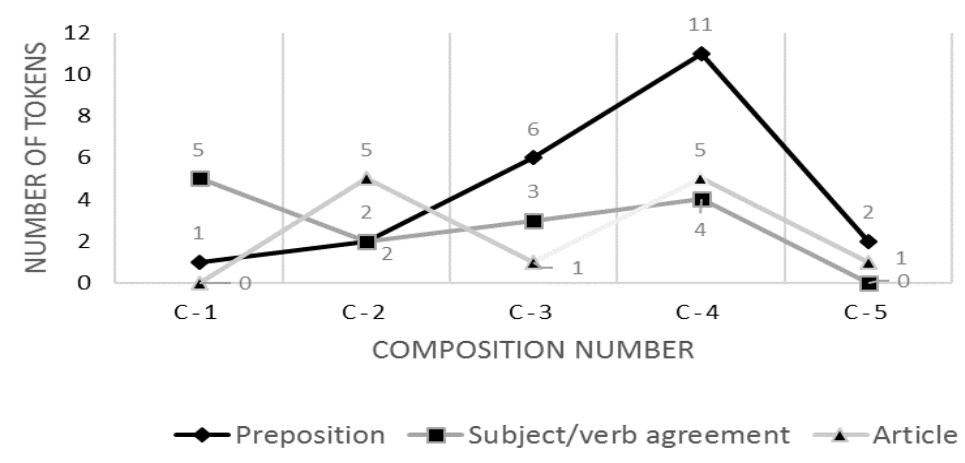

Figure 6: Cross-composition fluctuations in L1 top three sentence-level errors

The fluctuations in Figure 6 once again can be explained in terms of either increase of composition complexity or type. The most prominent of these errors, "preposition," appears to correspond with the steady increase in overall errors, referenced in the preceding paragraph and as what one would expect with an increase in the complexity of each successive composition. The same holds true for "subject-verb agreement" errors by L1 participants. This same group exhibits a somewhat different fluctuation pattern, however, when it comes to errors of the definite article. The surge in such errors at C-2 and C-4 suggest that, instead of increased complexity, the particular composition type may be the reason for their occurrence. As opposed to C-1 and C-3 which were more personal in nature and therefore, a type of writing with which L1 students were potentially more familiar, C-2 and C-4 were in contrast, more formal types of writing and therefore, ones to which L1 students were much less accustomed.

L2 errors at sentence level

TABLE 6:

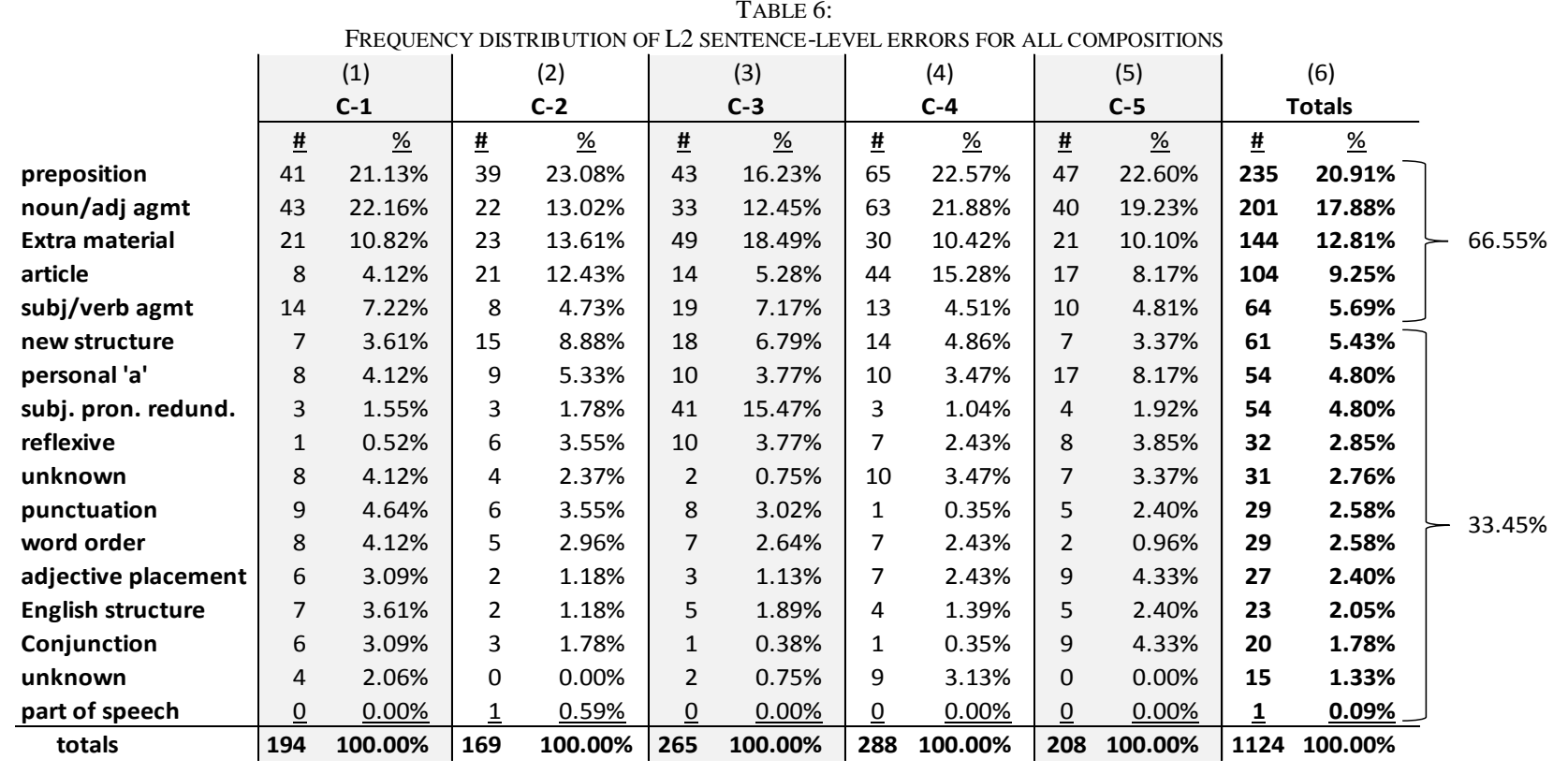


Table 6 shows the data for all sentence error categories (in order from highest to lowest) for L2 students.

According to the data in Table 6, a full $66.55 \%$ of all sentence-level errors committed by L2 participants is represented by errors in the first five error categories (from highest to lowest), as indicated in column (6), namely: 1) use of the wrong preposition $(\mathrm{n}=235 ; 20.91 \%) ; 2)$ lack of noun/adjective agreement $(\mathrm{n}=201 ; 17.88 \%) ; 3)$ extra (unnecessary) material $(\mathrm{n}=144 ; 12.81 \%) ; 4)$ a missing definite article $(\mathrm{n}=104 ; 9.25 \%)$; and 5) subject/verb agreement $(\mathrm{n}=64 ; 5.69 \%)$.

Some examples from the data of these five most common categories of L2 sentence level-errors are underlined and/or explained below:

(15) Wrong or missing preposition: “...jugar los deportes...” intended meaning: ‘....to play sports...' (Jugar 'to play' is a Spanish verb that requires the preposition $a$ 'to' before its complement.)

(16) Faulty noun/adjective agreement: “...una sonrisa luminoso.” intended meaning: '...a luminous smile' (An adjective in Spanish must agree in gender and number with the noun it modifies. Here the adjective must be in the feminine singular form luminosa since the noun it modifies sonrisa is in the feminine singular form.)

(17) Extraneous material: “...estudiando los estudios." intended meaning: ' ... studying.' (Here, the use of los estudios 'studies' is repetitive or redundant and is not necessary for the meaning of the sentence, so it may be deleted.)

(18) Missing definite article: “...todos miércoles.” intended meaning: '...every Wednesday.' (In Spanish, nouns with a generalized meaning must be preceded by the definite article. Also, the plural modifier todos 'all' requires the definite article in subsequent position.

(19) Faulty subject/verb agreement: “Ángela tuve una gran Aventura." intended meaning: 'Angela had a great adventure.' (The student incorrectly used the first person singular preterit form of the verb. The correct form should have been the third person preterit form, i.e., tuvo.)

All other sentence-level errors committed by L2 students of this study (totaling 33.45\%) occurred on average with less frequency. Some of these included a missing personal ' $a$ ' $(n=54 ; 4.8 \%)$; a redundant or unnecessary subject pronoun $(n=54 ; 4.8 \%)$, incorrect use of a reflexive pronoun $(n=32 ; 2.85 \%)$, and incorrect adjective placement $(n=27$; $2.4 \%)$, etc.

\section{L2 sentence-level trends between compositions}

If one compares the total number of sentence errors by L2 participants for each of the five compositions (represented in Table 6 by the last row of totals for columns (1) through (5)), we see that these students fared in a similar way to how they performed with word-level errors. In other words, in terms of sentence-level errors, L2 students of this study exhibited a slight drop (totaling an overall 25 tokens) between C-1 and C-2, followed by a pronounced increase of 96 tokens between C-2 and C-3. Total L2 errors continued to increase (even if only slightly by 23 tokens) between C-3 and C-4, but by C-5, total L2 errors dropped by a full 80 tokens. This pattern is strikingly similar to the pattern exhibited for word-level errors.

A closer look at L2 individual error categories across all compositions suggests that the most noticeable fluctuations appear in the categories of "preposition," "noun/adjective agreement," and "extra material" errors, as illustrated in Figure 7

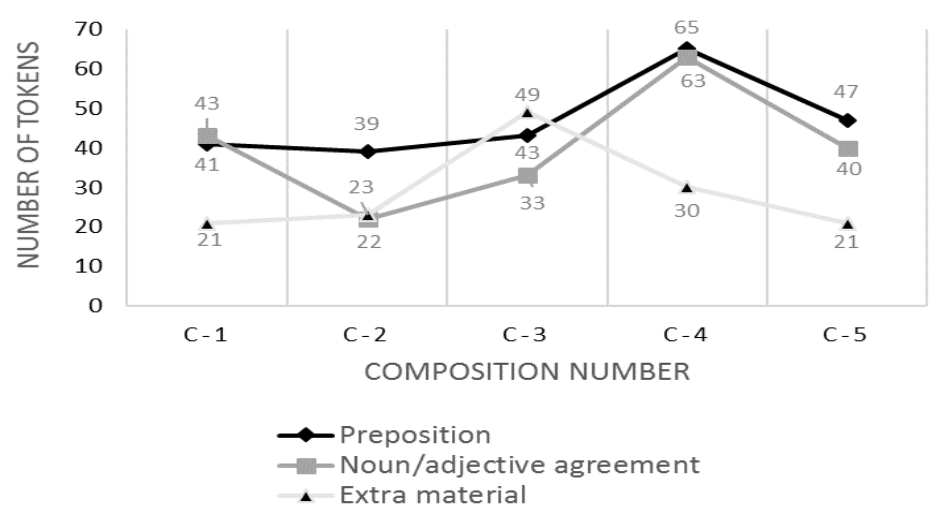

Figure 7: Cross-composition fluctuations in L2 top three sentence-level errors

Figure 7 suggests that both preposition errors as well as those involving faulty noun/adjective agreement follow a somewhat similar trajectory across compositions. More specifically, both of these errors appear to increase exponentially at $\mathrm{C} 4$, but then return to essentially the same level as they started at $\mathrm{C} 1$. Exhibiting a completely different pattern are those errors involving extraneous material. In this case, errors peaked at $\mathrm{C} 3$ and reduced significantly by $\mathrm{C} 4$, and then again, at $\mathrm{C} 5$. What might explain these patterns is nature of the compositions. $\mathrm{C} 4$, as explained in previous analyses, was a significantly more difficult composition to write in terms of formality and structure, and so it makes sense that more complex structural demands would contribute to significantly more errors in these categories. By the 
same token, the surge of extraneous material errors exhibited by this group at C3 may also be explained by the nature of the third composition, which as mentioned previously, was free style writing based on a personal narrative.

L1 and L2 sentence-level errors compared

When comparing the most common sentence-level errors between L1 and L2 learners of this study we see both similarities and differences in terms of the types of errors committed, their frequencies, or the degree of difficulty of one composition over another. Before making comparisons between L1 and L2 students which are composition-specific, we start with the comparison of overall error patterns in Figure 8.

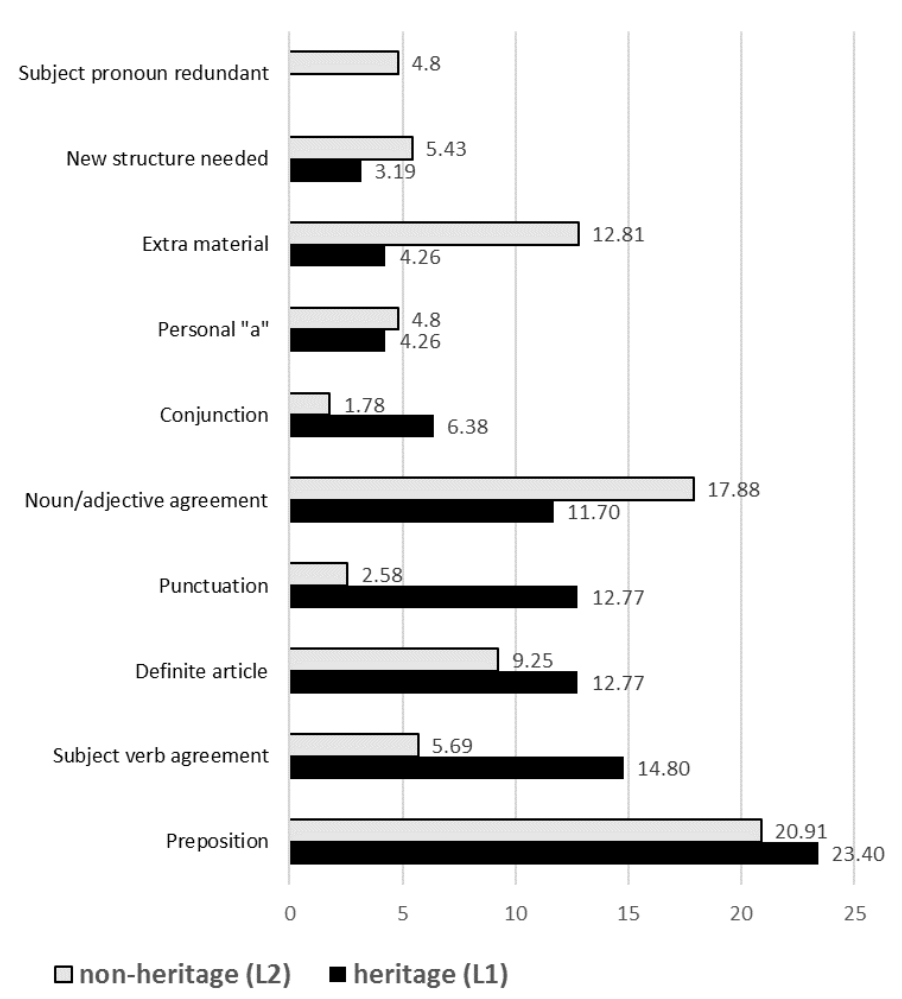

Figure 8: Comparative percentage distribution of overall L1 and L2 sentence-level errors

When comparing the most common sentence-level errors committed by L1 and L2 learners of this study we see once again, as was the case for errors at the word-level, that the same types of errors were committed by both groups, but for the most part they are distributed differently in terms of overall percentage of occurrence. One particular exception to this observation is the prominence of preposition errors by both groups.

Also interesting in terms of compared L1 and L2 word-level errors are the differences between the groups in terms of trends and fluctuations exhibited between the five compositions of this study. If one compares the composition error totals of Tables 5 and 6, isolated and repeated here as Figure 9, it is clear that both groups exhibited strikingly similar trends and fluctuations in each case between contiguous compositions:

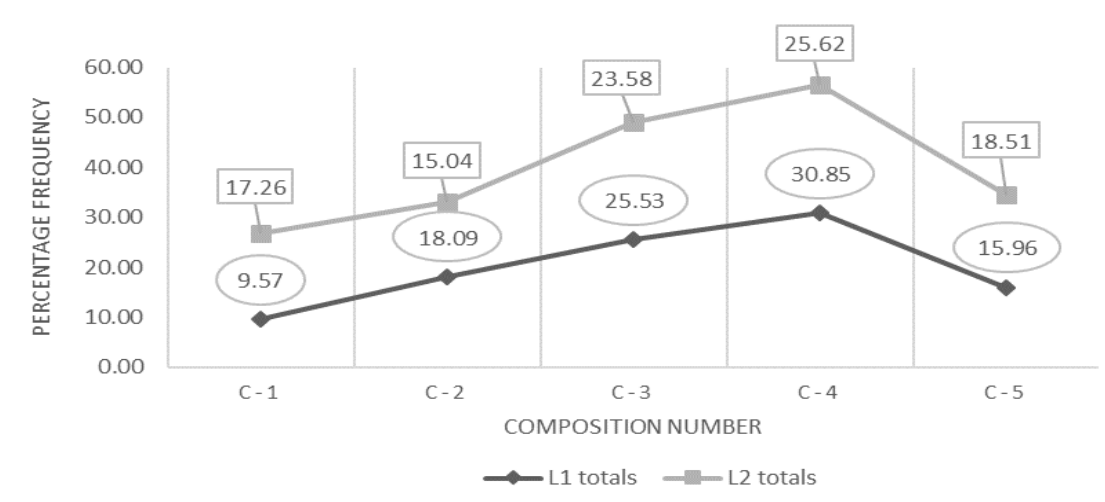

Figure 9: Overall L1 and L2 sentence error frequencies for all compositions 


\section{CONCLUSIONS}

The purpose of this study was to analyze and compare the word- and sentence-level errors exhibited by a cohort of fifteen students in a mixed classroom of L1 and L2 learners over a series of five compositions which targeted progressively higher writing proficiency levels. This final section of the paper highlights the major findings of this study and provides likely explanations for the results, along with some implications for how to improve instruction in classrooms with mixed L1 and L2 learners.

\section{L1 and L2 learners exhibit different error types and frequencies}

The data of this study showed that the L1 participants committed on average significantly fewer errors overall than their L2 peers, and that the majority of these errors were committed at the level of the word. L2 student participants, on the other hand, although they were found to make a large number of word-level errors as well, committed significantly more errors at the sentence level. These findings are not surprising for a number of reasons. First of all, most L1 students, particularly those of this study, typically have had little or no previous formal education in Spanish, ${ }^{4}$ and therefore, they are not as familiar with the written representation of words other than what they may read at home. This would explain the large number of errors in terms of written accents. Secondly, L1 students might be expected to fare better at the sentence level since sentence construction is a skill they practice constantly, even in spoken form.

L2 student participants also committed their fair share of errors at word level, but as the data showed, they were of a different type. For example, L2 students didn't have as great a difficulty with accents as their L1 counterparts did, but rather, their greatest problem was the use of the wrong word. Another significant problem for L2 participants at the word level was selection of the wrong tense, most usually dealing with aspect, in other words, the preterit versus the imperfect. Neither of these errors at the word level were as significant for L1 participants of this study. This finding is not at all surprising in that comparably, L2 students do not have the Spanish lexicon that L1 students can retrieve when necessary. Also, L1 students do not have to make the conscious choice that L2 students have to make when choosing the right tense.

The effects of time on improvement

Both L1 and L2 participant groups of this study appeared to follow a strikingly similar overall trajectory in terms of error improvement over time. In almost all cases, both L1 and L2 students decreased their total error output between first and second compositions, but then, took a reverse course and experienced sharp increases in errors between $\mathrm{C}-2$ and C-3, negligible increases between $\mathrm{C}-3$ and C-4, but then dramatic drops between C-4 and C-5. Considering this single common pattern over time for both participant groups, and for both word- and sentence-errors, it would appear that both L1 and L2 students of the study, rather than experiencing sustained improvement over time with the writing of each successive composition, instead began to reach a turning point at the time of the fourth composition where total number of errors began to stabilize, suggesting the beginning of a period of overall improvement, and by the last composition, considerable improvement.

This common trajectory for both groups of students makes sense when one considers that student revisions of their compositions are not finalized and submitted until the end of the semester and so dramatic improvement of the last composition would suggest that the process of intense correction of individual errors played a major role in the improvement of the final composition.

Implications of the data for improved instruction in combined classrooms

One of the greatest tasks for the instructor of any mixed-group classroom is to have to juggle the differing needs of its students. This is particularly true of a writing class in which individual student progress is the goal. Add to that the additional challenge of the lack of homogeneity within each of the L1 and L2 student groups. Despite these differences, it is the purpose of this section to evaluate the error patterns of this study and to make suggestions for how one might coordinate (in order of priority) different interventions in a combined classroom.

Major word and sentence errors that are common to both groups early on and repeat at a high rate throughout the semester-According to the data, word level errors that were most common to both groups early on and continued to be a problem thereafter were the appropriate use of accent marks, spelling, and wrong word choice. Likewise, sentencelevel errors common to both groups were incorrect or missing prepositions, noun/adjective agreement, subject/verb agreement, and missing definite articles. It would make sense that these errors should be prioritized as those that can be presented to both groups at the same time, but careful attention must be given to addressing the different ways both groups make the same mistake. ${ }^{5}$ One way to address most of these errors (except that of wrong word choice) is to incorporate lectures specific to these topics and to assign in-class and homework exercises and drills not just early on but continuing throughout the semester. Errors involving wrong word choice are a more difficult problem to address in a general sense because the degree to which students commit this error has been observed to vary with the individual. Also, word choice tends to be a different phenomenon for L1 students as it is for L2 students. One common way to

\footnotetext{
${ }^{4}$ L1 students are not a homogenous group. The situation explained here is currently the case for most L1 students enrolled in Spanish courses at the author's institution. Of course, students studying Spanish at other institutions may have a significantly different formal experience with Spanish and this therefore would affect the results of this study.

${ }^{5}$ For example, L1 student subject/verb agreement errors typically have to do with using plural verbs with collective nouns, whereas L2 errors tend to be a case of targeting the incorrect verb form from a memorized paradigm. Exercises would have to be different for each group in order to address these different phenomena.
} 
preempt some of these errors for both groups could be to share and review specialized vocabulary associated with a given assigned composition, perhaps with an additional prewriting exercise before students write their first draft.

Major word and sentence-level errors that are NOT common to both groups-Much like the previous category, because of the relative high number of errors, this category must also be addressed early in the semester. Unlike the previous case, however, these types of high frequency errors require division between the two groups. For example, some of the major errors particular to L2 students were those dealing with tense, mood, gender and the tendency to construct sentences with repetitive or unnecessary information. Whereas L1 students didn't exhibit these errors, they did have their own particular challenges, namely the conventions of capitalization and punctuation. These two very different needs by both groups could be addressed by common lectures, but separate drills and exercises would have to be assigned to each group so that they may practice their respective topical areas.

Composition-specific errors for both groups - This study also found that certain errors appeared with much higher frequency in certain types of writing than with others. According to the data, the composition with the highest frequencies of word-level errors for both L1 and L2 participants was C-3 in terms of accents, spelling, and wrong word errors. When it came to sentence-level errors, however, C-4 was the assignment exhibiting higher levels for both groups For L1 participants in terms of preposition and definite article errors. L2 students also demonstrated more difficulty with C-4, also with prepositions and use of the definite article, however, L2 students also exhibited comparatively high frequencies of other such errors as noun/adjective agreement, the use of extra or redundant material, and subject/verb agreement. The preponderance of word-level errors at C-3 and of sentence-level errors at C-4 for both groups of participants suggests an advantage in terms of how instruction can be geared toward addressing these errors. In other words, one could focus drills and exercises prior to the writing of C-3 on pitfalls that tend to occur at word level. Likewise, immediately following $\mathrm{C}-3$, and before the writing of $\mathrm{C}-4$, additional emphasis can be placed on the errors mentioned.

1) Persistent errors throughout all five compositions-Some errors such as incorrect spelling for both groups or incorrect use of reflexive pronouns for L2 students appeared at similar rates throughout all five compositions and would most likely improve from continuous intervention throughout the semester.

Sample size and future studies

The purpose of the summer research grant that funded this study was to collect and analyze authentic student error data from an existing Spanish composition class that could then be used to: 1) test current grading methods; 2) improve current course content and exercises; and 3) develop a new model for teaching composition to both L1 and L2 learners in mixed classrooms. As such, the sample size and make-up of L1 and L2 participants were determined by student enrollment for the course. The author recognizes the limitations of a sample for which one of its representative cohorts, in this case, L1 learners of the study, consists of only four students. As such, future expansion of this project might include a larger sample size of L1 students to test the results of this case study on a larger scale.

\section{REFERENCES}

[1] Carduner, J. (2008). “Teaching Proofreading Skills as a Means of Reducing Composition Errors.” Language Learning Journal 35: 2283-2295.

[2] DeHaan, P. \& Van Esch, K. (2005). “The Development of Writing in English and Spanish as Foreign Languages.” Assessing Writing 10: 100-116.

[3] Ferris, D. (2004). “The Grammar Correction Debate in L2 Writing: Where Are We and Where Do We Go from Here?" Journal of Second Language Writing 13 (1): 49-62.

[4] Lapuerta, P. \& Mejía, G. (2008). La escritura paso a paso. NJ: Pearson.

[5] Nas, M. \& Van Esch, K. (2014). “Acquisition of Writing in Second Language Spanish.” In Geeslin, K., Ed. The Handbook of Spanish Second Language Acquisition. MA: Wiley Blackwell.

[6] Roca de Larios, J., Murphy, L., \& Marín, J. (2002). “A Critical Examination of L2 Writing Process Research.” In Randsdell, S. \& Barbier, M. (Eds.), New Directions for Research in L2 Writing. Dordrecht: Kluwer Academic Publishers.

[7] Schneider, M. \& Connor, U. (1990). “Analyzing Topical Structure in ESL Essays: Not All Topics Are Equal." Studies in Second Language Acquisition 12: 411-427.

[8] Schoonen R., Snellings, P., Stevenson, M., \& van Gelderen, A. (2009). "Toward a Blueprint of the Foreign Language Writer: The Linguistic and Cognitive Demands of Foreign Language Writing.” In Manchón, R. (Ed.). Writing in Foreign Language Contexts: Learning, Teaching and Research. Bristol: Multilingual Matters.

[9] Silva, T. (1993). "Toward an Understanding of the Distinct Nature of L2 Writing: The ESL Research and its Implication," TESOL Quarterly 27: 657-677.

[10] Truscott, J. (2007). "The Effect of Error Correction on Learners' Ability to Write Accurately." Journal of Second Language Writing 16 (4): 255-272.

[11] Valdés, G., Haro, P., \& Echevarriarza, M. (1992). "The Development of Writing Abilities in a Foreign Language: Contributions towards a General Theory of L2 Writing." The Modern Language Journal 76: 333-352.

[12] Van Beuningen, C. (2010). "Corrective Feedback in L2 Writing: Theoretical Perspectives, Empirical Insights and Future Directions.” International Journal of English Studies 10 (2): 1-27. 


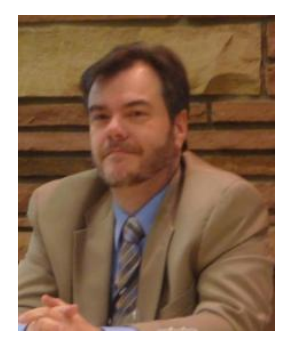

John M. Ryan earned his Ph.D. in Rhetoric, Composition, and Linguistics at Arizona State University in Tempe, Arizona, USA in 2008. He earned his Master's degree in Spanish linguistics, also from Arizona State, in 1991. He earned his Bachelor of Science degree in Spanish from Georgetown University's School of Languages and Linguistics in Washington, D.C. in 1985.

$\mathrm{He}$ is currently Associate Professor of Spanish Linguistics at the University of Northern Colorado. His research on the acquisition of verbs by children and adults has been published in such journals as the Journal of Child Language and Development, Teaching and Practice in Language Studies and Hispania, and his first book, The genesis of argument structure: Observations from a child's early speech production in Spanish (Germany: Lambert, 2012), traces the emergence of the verb phase in the developing language of a monolingual child learning Peninsular Spanish. Other interests include historical news discourse of the Italian American community and the reconstruction of proto Ibero Romance, for which he has recently authored several scholarly papers for different edited volumes.

Dr. Ryan is a member of the Linguist List International Linguistics Community, the Societas Linguistica Europaea, the Linguistic Society of America, the Rocky Mountain Modern Language Association, the Linguistic Association of the Southwest, the National Italian American Foundation, and the Italian American Historical Society. 